\title{
La cuestión de la lengua en el discurso tecnocientífico español del siglo XVI: el ejemplo de la economía
}

\section{Mariano Quirós García}

\section{OpenEdition}

\section{Journals}

Édition électronique

URL : https://journals.openedition.org/eve/857

DOI : 10.4000/eve.857

ISSN : 2425-1593

Éditeur :

Université de Savoie, Université Jean Moulin - Lyon 3

Référence électronique

Mariano Quirós García, « La cuestión de la lengua en el discurso tecnocientífico español del siglo XVI: el ejemplo de la economía ", Corpus Eve [En ligne], 1 | 2014, mis en ligne le 18 octobre 2013, consulté le 27 avril 2022. URL : http://journals.openedition.org/eve/857 ; DOI : https://doi.org/10.4000/eve.857

Ce document a été généré automatiquement le 27 abril 2022.

(c) Tous droits réservés 


\title{
La cuestión de la lengua en el discurso tecnocientífico español del siglo XVI: el ejemplo de la economía
}

\author{
Mariano Quirós García
}

\section{En el punto de partida}

1 La consolidación del denominado Estado Moderno se tradujo en esos grandes cambios políticos, sociales, económicos y culturales que caracterizan el siglo XVI. Asimismo, y como consecuencia de dicha metamorfosis, se desarrolló una nueva tecnología del poder que, a su vez, generó nuevas prácticas sociales y propició la reorganización de los distintos discursos científicos bajo el signo de la razón calculadora -del "espíritu de cálculo", de acuerdo con la denominación de Cirilo Flórez¹-, o, lo que es lo mismo, bajo el dominio absoluto de las matemáticas, extendido a todos los ámbitos de la realidad.

2 Junto a saberes especializados que contaban ya con siglos de tradición, como, por ejemplo, la medicina, la jurisprudencia o la astronomía, más o menos remozados en este período, surgieron otras nuevas disciplinas, auspiciadas y favorecidas incluso por la propia corona. Es el caso de la economía, que a lo largo del Renacimiento va a trascender los límites domésticos que le correspondieron desde la antigüedad, y va a configurarse, junto con el derecho, en uno de los puntales del nuevo estado.

Efectivamente, el fin de la Reconquista, el descubrimiento del Nuevo Mundo y su incorporación al que sería el último gran imperio occidental, supusieron para Castilla uno de sus periodos de mayor prosperidad y de esplendor. Fundamentando su actividad económica y política en los principios mercantilistas, que asociaban la riqueza con la posesión de metales y, por consiguiente, con la actividad colonial y el comercio monopolístico, los monarcas respaldaron la consolidación de las ferias y mercados urbanos, lo que se tradujo, además, en la intensificaron de sus relaciones con las principales plazas europeas, es decir, en su internacionalización ${ }^{2}$. De esta manera, al auge de la actividad bancaria que se produjo desde el último cuarto del siglo XV se 
sumó una radical transformación de los hábitos comerciales que afectó, de manera fundamental, al sistema cambiario, ya que, como recuerda García Sanz ${ }^{3}$, Medina del Campo, Medina de Rioseco y Villalón pasaron de ser "ferias de mercaderías" a "ferias generales" o "de pagos"4.

4 Por este motivo, la doctrina civil y moral que había prevalecido durante la Edad Media, centrada sobre todo en evitar la usura o interés que se llevaba en un mutuo, resultaba del todo insuficiente e ineficaz a la hora de establecer la justicia de los renovados tratos mercantiles. Mucho más aún si se considera la facilidad con la que dichos usos se alteraban, no solo por los vaivenes caprichosos del mercado, sino por la sutilidad con que los mercaderes procuraban soslayar esos escollos jurídicos y religiosos ${ }^{5}$. No obstante, como recordaba Tomás de Aquino, no le correspondía a la ley humana prohibir lo que era contrario a la virtud, sino lo atentaba contra la convivencia social (II ${ }^{a}$ IIae, q. 77, a. 1, ad 1); por ello, la justicia de los cambios, por ejemplo, fue un argumento exclusivamente ético, transformado en capítulo de vital importancia para los teólogos y canonistas españoles del siglo XVI.

5 Las Summae, los tratados De Iustitia et iure y los manuales de confesores y penitentes, que hasta entonces habían sido el marco habitual de tales reflexiones, resultaron géneros poco apropiados para un análisis exhaustivo del complejo mundo comercial, por lo que se optó por el tratado. En cuanto al latín, lengua distintiva de los ámbitos académicos y eclesiásticos, fue abandonado en muchos casos por razones pedagógicas, ya que los destinatarios de algunos volúmenes -clérigos y tratantes de manera fundamental- desconocían sus rudimentos. Finalmente, y por lo que atañe a su contenido, los primeros escritos áureos de carácter económico tendieron al pragmatismo y la casuística, esto es, a la reflexión sobre el oficio del mercader, razón que obliga a pensar que la identificación y enjuiciamiento de los usos comerciales dependía, en gran medida, del conocimiento de la praxis que poseía cada autor.

\section{Una ciencia sin nombre ${ }^{6}$}

6 Los antecedentes medievales del discurso y del lenguaje económico castellano remiten fundamentalmente a documentos y registros, ya sea de carácter notarial (testamentos e inventarios de bienes, capitulaciones matrimoniales, protocolos) o cancilleresco (aranceles, cuentas de recaudadores, albaranes), cuyo valor filológico es trascendental por su reflejo directo de las denominaciones vulgares ${ }^{7}$. Junto a ellos, sobre todo después de la determinación tomada por Alfonso X de unificar el derecho común con el uso del romance, habría que situar fueros, pragmáticas, recopilaciones de leyes, procesos de cortes y ordenamientos, a través de los cuales se intentaba regular la actividad financiera de Castilla. Por último, y por más extraño que pueda parecer, este tipo de léxico halló eco, como ya se ha señalado, en los confesionarios, de manera particular en el momento en que se abordaban el séptimo y el décimo mandamientos del decálogo no robarás y no codiciarás los bienes ajenos-, la avaricia y la simonía; de hecho, de acuerdo con el testimonio de los propios tratadistas áureos, la aparición de monografías romances de argumento mercantil se debió fundamentalmente a la rigidez y esquematismo intrínsecos al género penitencial, que imposibilitaban cualquier intento de descripción o de sistematización de las actividades mercantes y, por consiguiente, redundaban en la ya maltrecha formación de ciertos sectores eclesiásticos, en particular de los encargados de la administración de los sacramentos ${ }^{8}$. 
7 Por lo tanto, son estos los tres espacios medievales donde se testimonia de manera fundamental la descripción de la realidad mercantil española: documentación, jurisprudencia y teología, cada uno de ellos dotado de unas características propias, desde su mismo origen y razón de ser, hasta unos determinados rasgos que los individualizan desde el punto de vista literario y lingüístico. Tres áreas que continuaron estando plenamente vigentes a lo largo del Quinientos, si bien dos de ellas, desde el punto de vista del uso de la lengua vulgar, recibieron entonces un impulso decisivo: por una parte, la propia corona incentivó aún más la composición de obras en castellano destinadas a facilitar la práctica judicial ${ }^{9}$, a las que se sumarían algunos volúmenes vinculados más específicamente con el mundo del comercio, como el Doctrinal de confesores en casos de restitución (1552) de Diego del Castillo o el Arte de los contratos (1573) de Bartolomé de Albornoz. De otro lado, aunque los confesionarios y otros géneros penitenciales, como las sumas de casos de conciencia, continuaron granjeando fama a ciertos autores y pingües beneficios a muchos impresores, la metamorfosis radical del panorama económico español reclamó también una reforma teológica. La doctrina sumista medieval era a todas luces insuficiente para enjuiciar los nuevos hábitos de los comerciantes, por lo que, tras abandonar el latín por motivos pedagógicos, autores como Cristóbal de Villalón, Luis de Alcalá, Saravia de la Calle, Martín de Azpilcueta, Tomás de Mercado o Francisco García abordaron su modernización.

8 A lo largo del siglo XVI, a esta tríada de campos de actuación se unirían con gran pujanza la incipiente economía política, las matemáticas mercantiles y los primeros tratados dedicados a la práctica contable. De la primera forman parte los numerosos memoriales y opúsculos redactados por un no menos profuso grupo de arbitristas ${ }^{10}$, a quienes movía el deseo de solucionar algunos de los grandes conflictos del momento, particularmente relacionados con el abandono de las actividades agrícolas, con las finanzas de los endeudados monarcas y con los dineros de carácter público, que desaparecían allende los Pirineos apenas eran desembarcados en España. De esta manera se expresa Luis Ortiz:

Pues si todas estas exçelencias tiene España y otras ynfinitas que será ynposible de ver, ¿por qué no travajaremos e faremos lo que en nosotros es para aprovecharnos d'ellas, y azer lo primero serviçio a nuestro Dios y a Vuestra Magestad, y engrandeçer estos reynos y la república d'ellos? Para lo qual he trabajado por este bolumen pequeño poner algunos remedios y abisos cómo nuestra santa fe católica sea ençalsada, y el patrimonio real de Vuestra Magestad acreçentado, y el dinero que biene de Yndias y se cría en España no se lleve a poder de nuestros enemigos para que con ello agan guerra a Vuestra Magestad, y a otros ynnumerables provechos $^{11}$.

Por su parte, González de Cellorigo afirma:

Porque, considerando en qué podían, según los tiempos, ser mis servicios más aceptos, siendo para ello guiado por la continua senda que las ocupaciones y cuydados de Vuestra Magestad han descubierto, por ninguna parte juzgué poder llegar a la cumbre de mi desseo y acertar más con el de Vuestra Magestad, quanto en proponer lo que siempre tuve por muy necessario al reparo de la caýda y declinación grande que por las guerras, por la hambre, peste y mortandad y descuydo de los nuestros, esta monarchía, siendo la mayor, más rica y suprema de todo el orbe, es affligida y miserablemente tratada ${ }^{12}$.

Y Valle de la Cerda, justificando la utilidad de los montes de piedad, asevera:

Es justo que vea todo el mundo la gran prudencia de Vuestra Magestad en el felicíssimo principio de su govierno, y que, hallándolo tan empeñado, quiere, junto 
con su desempeño, començar a aliviar a sus vassallos y darles materia para relevarlos, con el tiempo, de todas las gravezas que al presente tienen, que será una gran corona para Vuestra Magestad en estos siglos y en los venideros, ultra de la que Dios le dará con el triunfo de vitoria tan cierta como tendrá de tan capital enemigo como es la usura, que siempre ha triunfado de las más poderosas monarquías, sin poderla sujetar con exércitos de leyes de emperadores y reyes, censuras y decretos de pontífices ${ }^{13}$.

De esta forma se convirtieron en magníficos testigos de ese período de desilusión y de decadencia material en el que se sumió España tras la breve pero intensa etapa de optimismo y prosperidad que le supuso el monopolio del comercio con el Nuevo Mundo ${ }^{14}$.

Por lo que se refiere a las matemáticas, con las que la economía ha mantenido siempre una estrecha vinculación, se ha señalado cómo a lo largo del siglo XVI es posible observar, a nivel europeo, una fuerte tendencia práctica a cubrir las necesidades de la navegación y el comercio ${ }^{15}$. En el panorama hispano gozaron de gran estima y se reeditaron en varias ocasiones ciertas aritméticas mercantiles, como las de Juan de Ortega, Gaspar de Tejeda, Marco Aurel o Juan Pérez de Moya; manuales de contadores, entre los que destacan el de Miguel de Eleizalde o el del mismo Pérez de Moya; y, por último, libros dirigidos a algunos gremios específicos, como los espejos de almutazafes - $u$ oficiales que debían contrastar los pesos y medidas- compuestos por los aragoneses Antonio Adrián de Ainsa y Pascual de Abensalero ${ }^{16}$, o los dedicados a las reducciones de monedas y metales preciosos, como el de Joán de Belveder, con los que parece inaugurarse, también en esta disciplina, una fase de declive ${ }^{17}$. Según se ha advertido, el fin perseguido era, ante todo y sobre todo, de carácter pragmático -pedagógico, moral-, orientado a allanar el trabajo cotidiano de los mercaderes y a proporcionar un adiestramiento que permitiera soslayar las trampas y engaños que tan a menudo salpicaban los tratos comerciales. De esta manera lo formula Juan de Ortega:

Yo, movido con el zelo que Dios es testigo y porque no pasasen tantos fraudes como pasan por el mundo acerca de las cuentas, pues que yo recebí este don de Dios, determiné con todas mis fuerças de trabajar de atajar este camino errado, por donde Dios tanto se ofende, como es con los fraudes hechos a los que poco saben. $Y$ por no ser redargüido de avariento y que guardava este tan gran tesoro debaxo de tierra, determiné de componer una arte de Arismética y Geometría, la qual arte imposiese a los hombres que esta sciencia quieran aprender y alcançar en el camino perfeto, no como gran arismético, mas como contador entre los menores ${ }^{18}$.

Y Juan Pérez de Moya redunda en esta misma idea cuando asegura que la [Aritmética] práctica trata la orden del investigar y hallar los números dudosos demandados, con el auxilio de la qual parte venimos en conoscimiento de lo que se ha de usar acerca de los tractos y mercaderías de la humana vida, para no defraudar ni ser defraudados ${ }^{19}$.

Joán de Belveder, por último, acredita su obra de la siguiente manera:

Por cuya causa, y de no estar corrientes las tales personas [mercaderes y tratantes] en el hazer de las cuentas de las dichas reduciones con sus interesses, muchas vezes suele aver fraude y engaño de una parte a otra con los herrores de la cuenta, causados unas vezes por descuydo, otras por no ser práticos y otras de ser algunas personas muy confiadas de sí mismos. Por evadir los dichos errores, fraude y engaño de cuenta a los tales, y a los que lo entienden bien ahorrarles el travaxo algunas vezes, propuse, con el mejor estilo que mis fuerças han podido alcançar, hazer este pequeño volumen ${ }^{20}$.

11 En cuanto al ámbito de la contabilidad, disponemos de dos textos para el siglo XVI: un anónimo Compendio y breve instrucción por tener libros de cuentas, deudas y de mercaduría 
(Barcelona, Claudio Bornat, 1565), traducción de un supuesto original francés que carece de preliminares; y el Libro de caja y Manual de cuentas de mercaderes, de Bartolomé Salvador de Solórzano, quien justifica la importancia de la obra en los siguientes términos:

En todas las artes y ciencias que oy se saben ha avido y ay artífices y maestros que las enseñen públicamente a todos los que las quisieren aprender. Y con ser esta una de las más necessarias e importantes para la república, hasta oy no se sabe que nadie la aya enseñado con la publicidad que las demás, sino tan solamente los que la han sabido la han enseñado a las personas que forçosamente han avido menester que la escrivan en sus libros por no se poder ellos ocupar en ello. Ni tampoco se sabe en nuestra España quién hasta oy aya escrito sobre ello, a cuya causa entre los que algo saben d'esto ha avido gran variedad en la ordenación y buena cuenta que se deve tener, porque cada uno la ha escrito por diferente modo y camino, como se vee por los libros de muchas personas donde se tiene esta cuenta y razón, que no se hallarán por maravilla dos libros de caxa con sus manuales, como sean de diferentes dueños, que conforme el uno con el otro, sino que cada uno está escrito por diferente estilo. Y porque en una cosa tan necessaria y forçosa para la república no aya tanta variedad, se ha tenido por acertado reduzirlo a la mejor orden, que es la que va escrita en el presente libro ${ }^{21}$.

12 Finalmente, dado el alcance que tuvieron y la preocupación que generaron las prácticas especulativas y los monopolios, así como las reflexiones sobre la distribución de las riquezas y sus repercusiones sociales, considerada su íntima vinculación con la vida cotidiana y con la idea de justicia -nihil sub sole novum-, podemos afirmar que el mundo del comercio y su jerga consiguieron abrirse paso y acomodarse entre los renglones de un buen número de obras. Entre ellas destacan las que prestaban atención particular al aumento progresivo e imparable del número de pobres $\mathrm{y}$, por consiguiente, al socorro de los mismos ${ }^{22}$; las destinadas a remediar los desastres morales y económicos que causaba una entrega desmesurada al juego ${ }^{23}$, o bien otras que reservaban algún espacio a cualquier argumento relacionado con el vil metal. De tal forma, que hasta es posible tropezarse con el nombre de Francisco de Osuna, considerado el primer escritor místico español, en algún elenco de moralistas españoles sobre temas económicos ${ }^{24}$, de manera fundamental a raíz de las consideraciones sobre la pobreza y la riqueza que expuso en la quinta parte de su Abecedario espiritual $(1542)^{25}$. Nombres y obras que conformarían un catálogo incompleto si no uniéramos a ellos ciertas composiciones pertenecientes al ámbito de la ficción, entre las que destacan algunos pasajes salidos de las péñolas de Cervantes y Quevedo, familiarizados con la doctrina de la moral y la política económicas, con la jerga comercial y creadores ellos mismos de términos que después serían aceptados por los propios especialistas ${ }^{26}$.

Con todo ello se evidenciaba la creciente preocupación que generaban los vaivenes del mercado y los usos del dinero en una sociedad en la que, a pesar de la oposición de los sectores tradicionalistas, comenzó a ejercer un papel cada vez más importante la burguesía mercantil y financiera. Nuevos ricos que supieron aprovechar las oportunidades económicas del momento, logrando un progresivo poder y un peso específico en la vida, en la mentalidad y en la cultura de la España precapitalista.

\section{La elección del castellano}

Como se ha apuntado en las páginas precedentes, parece que buena parte de los tratadistas abandonaron el uso del latín por motivos pedagógicos. No obstante, su 
elección lingüística dependió también en gran medida de la tradición discursiva o del círculo intelectual que enmarcaron su labor literaria. De esta manera, por ejemplo, por lo que se refiere tanto a los documentos privados y administrativos como a las obras del derecho civil, parece no existir duda alguna a la hora de decantarse por el romance, ya fuera por tratarse de una práctica secular, ya por las disposiciones dictadas al respecto por la legislación vigente en la época.

economistas políticos, por su parte, no sintieron en ningún momento la necesidad de justificar la utilización del castellano en sus escritos, dirigidos directamente al monarca, y, por lo tanto, omiten cualquier referencia a su opción lingüística.

Tampoco se lo plantean los matemáticos, dado que su fin más inmediato es didáctico, la enseñanza de mercaderes y laicos. Situación que, sin embargo, puede verse modificada cuando las intenciones son diferentes; razón por la cual Copérnico pudo afirmar que las "Mathemata mathematicis scribuntur" ${ }^{27}$. Es más: Marco Aurel, de origen alemán, se excusa por haber utilizado el castellano en la composición de su Aritmética, pero no en confrontación con el latín, sino con el alemán, su lengua materna:

Es verdad que no dexo de conoscer que podría ser, en todo y por todo, digno de gran pena y perpetua reprehensión en haverme querido atrever a componer y escrivir libros en lengua agena de mi natural, si ya mi voluntad de querer aprovechar y la necessidad que d'ello ay no desculpassen del todo a mi atrevimiento. Por lo qual, si el proseguir y ingerir de mis razones en esta obra no fueren como deven, no ay por qué dar fe a mis disfraçadas palabras, sino a la fe y verdad de la regla con que la obra se trata. Assí que, por ser cosa nueva lo que trato y jamás vista ni declarada, y podrá ser que ni aun entendida ni imprimida en España, me he atrevido a tratarla y escrivirla en lengua tan por entero repugnante a la mía. Y dado que esto sea assí, como dicho tengo, no dexo, empero, de someterme a toda regla de verdadera correción y rogar a todos los que mi libro tratar quisieren, reciban y corrijan mi obra, no con otra voluntad ni amor, sino con aquella que a mí me movió a querer aprovechar a todos ${ }^{28}$.

Por lo que respecta a la contabilidad aplicada, Salvador de Solórzano no muestra ninguna preocupación por razonar el uso de la lengua vulgar como código de comunicación, si bien la composición de la obra se fundamenta en motivos legislativos y didácticos:

La orden y estilo con que se tienen las cuentas en el libro de caxa y manual se ha entendido ser la mejor de todas, y por ser assí los años passados de 49 y 52 mandó Vuestra Magestad que por ella, y no por otra, la tuviessen todos los hombres de negocios naturales y estrangeros que residen en estos reynos, en que Vuestra Magestad bienaventuradamente reyna. $\mathrm{Y}$ aunque muchos lo saben y entienden, usan y exercen y cumplen lo que en esto está mandado, ay otros que faltan del cumplimiento d'ello por no lo entender, y para que lo sepan y se cumpla mejor el servicio de Vuestra Magestad y el bien d'estos reynos, y escusar muchos pleytos y diferencias que por no tener las cuentas por esta orden suele aver, persuadido y casi compelido a ello de personas que lo dessean saber, me dispuse a hazer este libro, por el qual los que no entienden ni saben este estilo lo podrán aprender, y los que lo supieren lo usarán más perfetamente, y los que no tienen obligación de guardar esta ley, assimismo, si quisieren, se pueden servir y aprovechar d'él ${ }^{29}$.

18 Este panorama, no obstante, es diametralmente opuesto al que encontramos en los textos circunscritos a la esfera de la teología, desde la cual, como se ha indicado, se desarrolló la primera y más notable labor de conceptualización de la nueva realidad económica y financiera española, estableciendo, de esta forma, los cimientos de la moderna ciencia económica. Disímil por completo ya que parece ser el único ámbito en 
que los autores sienten una constante preocupación por excusar el uso del castellano, incluso en aquellos casos en los que se contaba ya con una sólida tradición que avalaba tal empleo. Es el caso del Manual de confesores y penitentes de Martín de Azpilcueta, primero redactado en portugués y en 1556, con motivo de su tercera edición, traducido al castellano, a pesar de que, a juicio del propio autor, "son lenguajes que no passan los montes Pyreneos", en confrontación con el latín, que era la "común lengua de la mayor parte de la Europa" ${ }^{30}$.

19 Más comprometida parece la situación en la tratadística, donde se aprecia una mayor insistencia de los autores por excusar su entrega a la lengua vulgar, apoyándose, una vez más, en la falta de una correcta formación y en el desconocimiento de los idiomas clásicos por parte de confesores y mercaderes. Así, Cristóbal de Villalón arguye en su Provechoso tratado de cambios y contrataciones:

La simplicidad de mi buena intención, reverendíssimo y muy yllustre señor, me fuerça a cometer hazañas que a todo el mundo parecerán temeridad. Dos cosas hago, las quales corren a la ygual: atreverme a escrivir y mostrar tanta confiança de mí, que vuestra señoría lo aya de ver. De la primera culpa me escusa la importunidad de un grande amigo mío mercader, que me pidió con grande instancia que le escriviesse alguna cosa en la materia de cambios y usuras; y, por hablar con él, lo traté en lengua familiar. Trabajé cómo, cumpliendo con él, se hiziesse algún provecho al común, por ver la gran necessidad que tienen los hombres de rienda en el negociar el día de oy, y principalmente por advertir a los confessores en cuyas manos caen los tales, que, por no tener doctrina y experiencia en esto, los dexan passar y les dan más licencia que es razón ${ }^{31}$.

También Luis de Alcalá asegura que su Tratado de los préstamos fue compuesto a instancia de confesores y laicos, para alumbrar a unos en su oficio divino y desengañar a los otros de las supuestas ventajas de ciertas operaciones financieras:

Por estas razones y por no querer, assimismo, del todo esconder debaxo la tierra el pequeño talento que de nuestro Señor rescibí, aunque, de verdad, con miedo y temor de mi poco saber, copilé lo que aquí va. Y después de mostrado a muchos hombres doctos, y passado por el examen que al principio se pone, he trabajado que se imprima para gloria de Dios y provecho de unos y otros. Y la intención d'este provecho me le hizo poner en romance, porque assí los que defendían su opinión, como los que dessean saber lo cierto y no saben latín, no dexen de entender lo que $\operatorname{digo}^{32}$.

21 Y Saravia de la Calle, el más vehemente en este tipo de razonamientos, inicia su Instrucción de mercaderes con esta impetuosa argumentación:

Y en la sciencia más dificultosa, que es del regimiento de las ánimas, cuya governación principalmente consiste en el sacramento de la penitencia, ay escripto tanto en la lengua vulgar, que ay quasi tantos confessionarios, que llaman, como confessores; porque, como la ygnorancia de muchos sacerdotes sea tanta y el atrevimiento de confessar sea mayor, los que algo saben, por alumbrarlos en algo, con facilidad escriven, viéndose, como dizen, entre los ciegos rey. Alabo su piadoso zelo y desseo; mas, si es secundum scienciam, júzguenlo los que lo pueden remediar. No sé yo qué aprovechan los confessionarios escriptos en romance para los que no saben latín, pues, escriptos en latín para los que saben latín solamente aprovechan tan poco. Si con solo saber latín e tener confessionarios en romance basta para ser confessor, bastará al latino que tenga libros de Medicina para ser médico, de Astrología para ser astrólogo, e assí será el gramático omnis homo ${ }^{33}$.

O lo que es lo mismo: un confesionario, aunque escrito en castellano, poco valor tenía para los faltos de formación; tan poco, como el escrito en latín, que solo aprovechaba a los universitarios y entendidos: 
Pues, si el latín vale tan poco, como es notorio, ¿qué valdrá el romance solo? Pues luego poco provecho hazen los escriptores celosos a los confessores ygnorantes en darles confessionarios en romance, antes pienso que en gran manera los dañan, porque, con tenerlos, les dan atrevimiento que confiessen, lo qual, sin ellos, no osarían hazer; y, con no entendellos, caen en grandes errores, pues no son menos dificultosas las cosas de consciencia en romance que en latín. [...] Por lo qual, con mucha razón se defiende que la Sagrada Escriptura no se lea en vulgar, porque no aprovecha el oýr de las palabras sin entender los mysterios, sino para caer en errores $^{34}$.

Saravia, por consiguiente, sentía también escrúpulos ante los inconvenientes que podía causar la utilización del castellano, puesto que con él se destruía esa muralla defensiva que el latín había levantado entre los laicos y los fundamentos teológicos de la doctrina cristiana. Por ello,

me he detenido muchas vezes de no osar escrevir aquesta materia en vulgar, hasta que he visto la grande necessidad que ay, porque los confessores simples no dexan de confessar, y en sus confessionarios no tienen resoluta aquesta materia ni declarada, e ya la mayor parte del mundo está puesta en tráfagos e compras e arrendamientos; no solo ciudadanos, labradores e mercaderes, mas hidalgos que, con oficios no devidos, se mantienen en tratos y mercaderías ${ }^{35}$.

24 La labor de estos pioneros vigorizó y afianzó la vertiente romancista, de tal manera, que ya en 1594 el portugués Manuel Rodrigues afirma:

Escrivile [este libro] en lengua vulgar para que con más facilidad puedan usar todos d'él y nadie halle cerrada la puerta de su provecho, quanto más que está ya tan illustrada esta lengua de lúcidos y doctos escriptos, que es digna de qualquiera obra $^{36}$.

Lo cual permitió que los propios teólogos abandonaran paulatinamente este tipo de especulaciones e invirtieran sus esfuerzos en la búsqueda de ese estilo claro, natural, carente de afectación, al que aspiraba buena parte de los escritores áureos:

[...] mi cuidado principal fue tener siempre ante los ojos el talento y condición de la gente a quien mostraba, diciendo en cada punto y contrato solamente lo que bastase, no todo lo que para ornato y hermosura de la obra se pudiera decir, aunque bien se me figuró que, siguiendo tanta resolución, había de salir la doctrina algo desnuda y fea, porque la substancia sola de la verdad, dado que por ser verdad es en sí hermosísima, no parece tal a nuestra vista lagañosa si no se pone algún color de facundia y elegancia y se viste de argumentos y razones con algunas galas de antigüedades. Mas consideré que vestida de todas sus ropas, que son la eficacia de razones en que estriba y la autoridad de los doctores que la afirman, abultaría tanto con su corpulencia que no cabría la materia de toda esta obra en dos grandes tomos. Lo cual fuera causa que, por el título de perfecta y galana que cobrara, perdiera el de provechosa y se frustrara nuestro intento, que es mostrar a muchas personas que sin lumbre de leyes divinas ni humanas se meten atrevidamente en muy espesas tinieblas de contratos, porque no hubiera mercader que arrostrara a lección tan larga, especialmente que muchas de las causas que se pudieran dar son difíciles de entender a quien carece de filosofía moral, do tienen sus principios y fundamentos, los cuales es necesario se presupongan para entender científicamente las conclusiones que van aquí deducidas ${ }^{37}$.

\section{A modo de conclusión}

26 A pesar de que el conocimiento del latín resultaba imprescindible para cualquier disciplina científica, la reflexión sobre la propia lengua era esencial, puesto que a lo largo del Renacimiento el castellano se empezó a utilizar como código de comunicación 
de contenidos científicos. No obstante, y como recordaba hace ya algunos años López Piñero, "la lengua vulgar dominó en las materias de carácter aplicado y en los enfoques ajenos al mundo académico" ${ }^{38}$, aunque a la universidad habría que unir también puesto que no siempre coincidían- el peso específico del estamento eclesiástico y la convicción de que ciertos contenidos doctrinales no debían divulgarse, sobre todo en una época de agitación y efervescencia espiritual.

Tal es la situación que desvela la primitiva prosa económica, cuyos fundamentos, a falta de una disciplina propia e independiente, hay que buscar en ámbitos tan diversos como las matemáticas, la contabilidad, la economía política, el derecho y, de manera esencial, la teología, así como en obras y autores muy diferentes. Las declaraciones propuestas en este trabajo muestran cómo estos pioneros eran conscientes de la novedad de sus escritos, vinculados a una realidad en constante cambio, aunque solo los teólogos reflexionan sobre el significado profundo de la decisión de usar el castellano como vehículo de comunicación especializada y de divulgación. A la exigencia de mantenerse fieles a los círculos universitarios y eclesiásticos se impuso, en ocasiones de manera insoslayable, la necesidad de identificar, definir y valorar determinadas realidades mercantiles para poder formular un patrón ético de conducta religiosa y social.

En aras de una formación más profunda de los sacerdotes encargados de la cura de almas, particularmente de los confesores, y de ese "bien común" que esgrime buena parte de los autores como fin último de sus escritos, comenzó a forjarse una auténtica doctrina vernácula que sentaría las bases de la moderna ciencia económica española.

\section{NOTES}

1. Flórez, Cirilo, "Otra cara del humanismo", en M. Jesús Mancho (dir.) y Cristina Blas (coord.), Pórtico a la ciencia y a la técnica del Renacimiento, Salamanca, Junta de Castilla y León/ Universidad de Salamanca, 2001, p. 28. Por su parte, José Antonio Maravall hablaba ya de "los principios de mensurabilidad y calculabilidad que inspiran las creaciones de la época" en su Estado moderno y mentalidad social, Madrid, Revista de Occidente, 1972, vol. 1, p. 68.

2. Sin embargo, no hay que olvidar que dicha vinculación se había iniciado ya durante los siglos XIV y XV gracias a la exportación de lana de oveja merina, especialmente a Flandes, Francia e Inglaterra, de donde Castilla importaba, a su vez, las manufacturas textiles allí elaboradas (vid. Sánchez del Barrio, Antonio, "Comercio y ferias en tiempo de Isabel la Católica", Alicante, Biblioteca Virtual Cervantes, 2005, [en línea]: http://www.cervantesvirtual.com/servlet/ SirveObras/01048741107818320770035/index.htm).

3. García Sanz, Ángel, "El contexto económico del pensamiento escolástico: el florecimiento del capital mercantil en la España del siglo XVI”, en Enrique Fuentes Quintana (dir.), Economía y economistas españoles. 2: De los orígenes al mercantilismo, Barcelona, Galaxia Gutenberg, 1999, p. 155.

4. Para un acercamiento a la terminología cambiaria vid. Quirós García, Mariano, "Sistemática de los cambios y unidades léxicas complejas en los tratados económicos renacentistas", Foro Hispánico (41, 2010), p. 149-167. 
5. Vid. Saravia de la Calle, Instrucción de mercaderes, Medina del Campo, Pedro de Castro, 1544, fol. LXXIIr; Mercado, Tomás de, Suma de tratos y contratos [1569 $\left.{ }^{1}-1571^{2}\right]$, ed. de N. Sánchez Albornoz, Madrid, Instituto de Estudios Fiscales/ Ministerio de Hacienda, 1977, vol. 1, p. 355-356.

6. Remedo el título del trabajo de Jean Vilar, "Des idées, des mots pour "des choses": L'Économie, savoir sans nom de l'Espagne classique”, en Les mentalités dans la Péninsule Ibérique et en Amérique Latine aux $\mathrm{XVI}^{e}$ et $\mathrm{XVII}^{e}$ siècles. Histoire et problématique. Actes du XIII ${ }^{e}$ Congrès de la Société des Hispanistes Français de l'Enseignement Supérieur (Tours, 1977), Tours, Université de Tours, 1978, p. 33-59.

7. Vid. Gual Camarena, Miguel, Vocabulario del comercio medieval. Colección de aranceles aduaneros de la Corona de Aragón (Siglos XIII y XIV), Tarragona, Diputación Provincial, 1968, p. 24; Sesma, José Ángel, y Líbano Zumalacárregui, Ángeles, Léxico del comercio medieval en Aragón (Siglo XV), Zaragoza, Institución "Fernando el Católico", p. 17-18. Hasta el día de hoy no contamos más que con estas dos monografías de carácter lexicográfico, dedicadas ambas al comercio medieval en la corona de Aragón y su vocabulario. Se remite a ellas por lo que se refiere a la clasificación y descripción de las fuentes (Gual Camarena, op. cit., p. 24-48; Sesma y Líbano, op. cit., p. 15-22).

8. Vid. Quirós García, Mariano, "Los tratados romances de moral económica en el Renacimiento español”, en Luis Santos, Julio Borrego, Juan Felipe García Santos, José Jesús Gómez Asencio y Emilio Prieto (eds.), Palabras, norma, discurso. En memoria de Fernando Lázaro Carreter, Salamanca, Universidad de Salamanca, 2005, p. 966-968; íd., "Non furtum facies: confesionarios y economía en la España del siglo XVI”, en prensa. La gran tradición latina, dogmática y escolástica del derecho y de la teología, que aún habría de cosechar grandes frutos a lo largo del Renacimiento con la denominada Escuela de Salamanca, había acogido el tratamiento de determinados hechos económicos en el contexto de las Summa theologica, los comentarios a la Secunda Secundae de santo Tomás y los tratados De Iustitia et iure. Pero su carácter totalizador tampoco permitía un acercamiento demasiado exhaustivo a la realidad mercantil, por lo que en el siglo XVI, vinculados de una manera o de otra al magisterio de Francisco Vitoria, aparecieron algunos tratados más específicos como los de Juan de Medina, Diego Laínez, Luis de Molina o Diego Covarrubias y Leiva (vid. Grice-Hutchinson, Marjorie, El pensamiento económico español (1177-1740), Barcelona, Crítica, 1982, p. 107-161).

9. Razón por la cual Diego del Castillo, a petición del rey, se vio en la obligación de traducir al castellano su Tratado de cuentas (Burgos, Alonso de Melgar, 1522). Por otra parte, se continuó promocionando la confección de recopilaciones y repertorios alfabéticos de leyes, como los de Andrés Martínez de Burgos (Reportorio universal de todas las premáticas y capítulos de Cortes, Medina del Campo, Guillermo de Millis, 1551) y Hugo de Celso (Reportorio universal de todas las leyes d'estos reynos de Castilla, comp. Andrés Martínez de Burgos, Medina del Campo, Juan María da Terranova y Jacome de Liarcari, imprenta de Francisco del Canto, 1533³). Existe edición de los tres textos en Mancho Duque, M. Jesús (dir.), y Quirós García, Mariano (coord.), La ciencia y la técnica en la época de Cervantes: textos e imágenes, Salamanca, Universidad de Salamanca, 2005.

10. Dado el matiz peyorativo que desde sus orígenes adquirió el término arbitrista como inventor de proyectos hacendísticos disparatados, sobre todo a partir de algunas obras de Cervantes y Quevedo (vid. Pascual Rodríguez, José Antonio, y Quirós García, Mariano, “Caballería y economía: Cervantes entre dos mundos fictivos”, en VV. AA., El Quijote y el Tribunal de Cuentas, Madrid, Tribunal de Cuentas/ Imprenta Nacional del BOE, 2005, p. 184-186), se ha preferido hablar en este caso de economistas políticos, por más que, como indicaba Grice-Hutchinson (op. cit., p. 190), autores como Luis Ortiz y Martín González de Cellorigo, considerados por todos como excelentes economistas, no dejaron de ser, sin duda alguna, arbitristas. Para una primera aproximación histórica a la semántica de arbitrio y arbitrista puede consultarse el ya clásico trabajo de Jean vilar, Literatura y economía. La figura satírica del arbitrista en el Siglo de Oro, Madrid, Revista de Occidente, 1973, particularmente p. 23-58.

11. Ortiz, Luis, Memorial para que no salgan dineros del reino, mss. 1558, fol. 6v-7r. 
12. González de Cellorigo, Martín, Memorial de la política necesaria y útil restauración a la república de España y estados de ella, Valladolid, Juan de Bostillo, 1600, Dedicatoria a Felipe III, fol. 2v.

13. Valle de la Cerda, Luis, Desempeño del patrimonio de Su Magestad y de los reynos [...] por medio de los erarios públicos y montes de piedad, Madrid, Pedro de Madrigal, 1600, Dedicatoria a Felipe III, fol. 3r-v; en Mancho, M. J Jesús (dir.), y Quirós García, Mariano (coord.), La ciencia y la técnica..., op. cit.

14. Vid. Grice-Hutchinson, op. cit., p. 162-233.

15. Vid. Rey Pastor, Julio, Los matemáticos españoles del siglo XVI, Madrid, Junta de Investigaciones Histórico-Bibliográficas, 1934, p. 52-53; Mancho, M. Jesús, “Oriente y occidente en el léxico de las matemáticas del Quinientos”, en Mar Campos, Rosalía Cotelo y José Ignacio Pérez Pascual (coords.), Historia del léxico español, A Coruña, Universidade da Coruña, 2007, p. 97-107.

16. El Libro de almutazafes de este último vio la luz al finalizar la primera década del siglo XVII (Zaragoza, Lorenzo de Robles, 1609).

17. Vid. Rey Pastor, op. cit., p. 132-133.

18. Ortega, Juan de, Conpusición de la arte de la Arismética y de Geometría, León de Francia, Maistro Nicolau de Benedictis (por Ioannes Trinxer), 1512, fol.1v; en Mancho, M. Jesús (dir.), y Quirós García, Mariano (coord.), La ciencia y la técnica..., op. cit.

19. Pérez de Moya, Juan, Arithmética práctica y speculativa, Salamanca, Mathías Gast, 1562, p. 2; en Mancho, M. Jesús (dir.), y Quirós García, Mariano (coord.), La ciencia y la técnica..., op. cit.

20. Belveder, Joán de, Libro general de las reduciones de plata y oro, Lima, Antonio Ricardo, 1597, Epístola al lector, fol. Vr; en Mancho, M. Jesús (dir.), y Quirós García, Mariano (coord.), La ciencia y la técnica..., op. cit.

21. Salvador de Solórzano, Bartolomé, Libro de caxa y Manual de cuentas de mercaderes, Madrid, Pedro Madrigal, 1590, Prólogo al lector.

22. Línea inaugurada por Juan Luis Vives con su De Subventione pauperum (1525) y que en castellano siguieron Juan de Medina, Domingo de Soto, Miguel Giginta o Cristóbal Pérez de Herrera.

23. Es decir, los "remedios" de jugadores, como los de Pedro de Covarrubias, Francisco de Alcocer o Adrián de Castro.

24. Vid. Alonso Rodríguez, Bernardo, "Monografías de moralistas españoles sobre tomas económicos. Siglo XVI (II)", en Repertorio de Historia de las Ciencias Eclesiásticas en España. Vol. 6: Siglos I-XVI, Salamanca, Universidad Pontificia, 1977, p. 144, 182-184.

25. Sin embargo, no deja de resultar chocante el hecho de que, de los varios capítulos que este franciscano dedicó al análisis de las causas por las cuales había tantos pobres en la España de la época, de las que llega a enumerar hasta catorce, Alonso Rodríguez solo seleccionara dos pequeños fragmentos, y no precisamente los más significativos. A este respecto puede consultarse Francisco de Osuna, Abecedario espiritual V y VI partes, ed. de Mariano Quirós García, Madrid, FUE, 2002, vol. 1, p. 89-111.

26. Vid. la nota 10 del presente trabajo.

27. Copérnico, Nicolás, De Revolutionibus orbium coelestium, Norimbergæ, Ioh. Petreium, 1543, Praefatio authoris.

28. Aurel, Marco, Libro primero de Aritmética algebrática, Valencia, Joán de Mey, 1552, Al lector; en Mancho, M. Jesús (dir.), y Quirós García, Mariano (coord.), La ciencia y la técnica..., op. cit. Puede completarse la información aquí ofrecida con dos trabajos de M. Jesús Mancho: "La lengua española, vehículo de divulgación científica en el Renacimiento”, en M.a Jesús Mancho (dir.) y Cristina Blas (coord.), Pórtico a la ciencia..., op. cit., p. 45-84; "Los prólogos de la literatura científica del Renacimiento: la cuestión de la lengua”, en M. a Luisa Lobato y Francisco Domínguez (eds.), Memoria de la palabra. Actas del VI Congreso de la AISO, Madrid/ Frankfurt, Iberoamericana/ Vervuert, 2004, vol. 2, p. 1229-1243.

29. Salvador de Solórzano, Bartolomé, op. cit., Al rey. 
30. Azpilcueta, Martín de, Manual de confesores y penitentes, Salamanca, Andrea de Portonariis, 1556, Al pío lector. Otro asunto bien distinto es que él mismo percibió que este género resultaba demasiado estrecho ante cualquier intención dogmatizante, por lo que configuró la obra como un auténtico tratado, algunos de cuyos apéndices -cinco comentarios resolutorios añadidos a la edición de 1556- llegarían a gozar de publicación independiente.

31. Villalón, Cristóbal de, Provechoso tratado de cambios y contrataciones de mercaderes y reprobación de usura, Valladolid, Francisco Fernández de Córdova, 1541, fol. Iv.

32. Alcalá, Luis de, Tratado en que a la clara se ponen y determinan las materias de los préstamos, Toledo, Juan de Ayala, 1543, Carta al benigno lector.

33. Op. cit., fol. IIr-v.

34. Ibid., fol. IIIr.

35. Ibid., fol. IIIr-v.

36. Rodrigues, Manuel, Suma de casos de conciencia [15941ㅡ, Salamanca, Juan Fernández, 1596³ , vol. I, $\mathrm{Al}$ lector.

37. Mercado, Tomás de, op. cit., p. 20.

38. López Piñero, José M., Ciencia y técnica en la sociedad española de los siglos XVI y XVII, Barcelona, Labor, 1979, p. 140.

\section{RÉSUMÉS}

En el siglo XVI se publican los primeros testimonios de la que puede considerarse la primitiva prosa económica castellana, circunscritos a diversas áreas de conocimiento como la teología, el derecho, la economía política, las matemáticas o la contabilidad. Los autores de tales volúmenes eran conscientes de la novedad de sus escritos, así como de la trascendencia de sus elecciones lingüísticas, aunque su pertenencia a distintos círculos intelectuales y su adscripción a determinadas tradiciones discursivas se tradujeron en diferentes actitudes con respecto al uso del castellano como código de comunicación. En el presente trabajo se analizan tales posturas, prestando particular atención a la argumentación ofrecida por los propios protagonistas, que abarca desde la intención didáctica y moralizante hasta la búsqueda de un «bien común», cuasi universal. Entre ambas posturas, además, es posible descubrir distintos matices que apoyaron definitivamente la elección del vulgar como lengua de la cultura hispánica, también de la economía, que daba así sus primeros pero firmes pasos hacia su consideración como ciencia.

\section{INDEX}

Palabras claves : Renacimiento español, discurso tecnocientífico, economía, defensa del castellano

Index géographique : domaine hispanique

Index chronologique : XVIe siècle 


\section{AUTEUR}

\section{MARIANO QUIRÓS GARCÍA}

Mariano Quirós García es Científico Titular del Instituto de Lengua, Literatura y Antropología del Centro de Ciencias Humanas y Sociales del CSIC. Ha trabajado fundamentalmente en la edición de textos renacentistas y en la historia del léxico especializado, prestando particular atención a los ámbitos de la mística y de la economía. 